\title{
Jurnal \\ Teknologi \\ DAMAGE ASSESSMENT BASED ON MODAL ANALYSIS OF PIPE STRUCTURE
}

\author{
Sakhiah Abdul Kudus*, Yasuo Suzuki, Masahide Matsumura, \\ Kunitomo Sugiura
}

Department of Civil and Earth Resources Engineering, Graduate School of Engineering, Kyoto University, Kyoto, 615-8540, Japan
Article history

Received

3 October 2017

Received in revised form

27 February 2018

Accepted

30 March 2018

Published online

1 August 2018

*Corresponding author sakhiah88@ymail.com

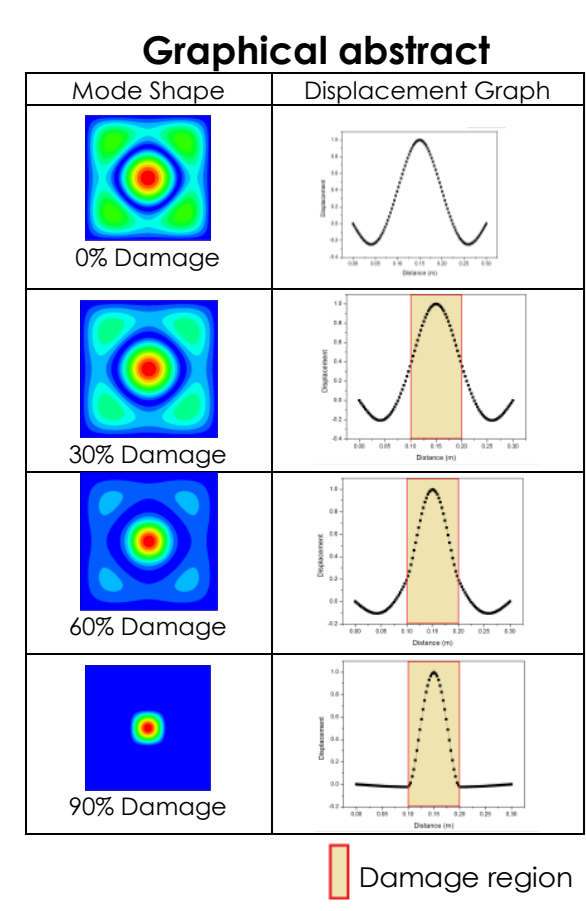

\begin{abstract}
The degradation of steel pipe structures, especially thickness reduction due to corrosion is a common problem found in marine structures. This calls for an evaluation of the thin structure's structural health condition to ensure its safety and reliability. This study investigates the effect of reduction in pipe wall thickness on the pipe structure's dynamic behaviour using the fundamental modal parameter as the indicator for its health condition. A finite element analysis utilising Abaqus software has been adapted to model the problem. The corrosion problem was simulated by thickness reduction on six damage cases. The influence of the severity and position of damage on the observed mode upon the percentage of natural frequencies' reduction and localisation of mode shape of the pipe structure are subsequently displayed. Four mode shapes and its corresponding natural frequency were extracted from baseline model to further evaluate the sensitivity of the selected mode towards the presence of damage. The study found that severe damage in pipe structure leads to significant reduction of natural frequency and localisation of mode shape in the vicinity of damaged region. The vibration results summarised in this paper may serve as a benchmark for researchers and as a reference for design engineers.
\end{abstract}

Keywords: Steel pipe, Modal analysis, Finite element analysis, Mode shape, Natural frequency

\subsection{INTRODUCTION}

Corrosion which cause loss of thickness section in marine structures can lead to damage that significantly weakens its stiffness, toughness, and durability and could have adverse effects on its functionality. Additional repetitive cyclic loads from the ocean or secondary to major events like earthquakes may escalate the damage further. Thus, aged structures merit serious concern as weakened and damaged structures are both a safety hazard and leads to poor productivity and efficiency. As such, engineers across different fields seek to detect structural damage as early as possible.

Structural health monitoring (SHM) and nondestructive testing (NDT) are among the most commonly used methods of assessing structural damage due to not causing harm and damage to the structure during the monitoring process. In addition, the application of NDT method for damage assessment is highly accurate but this method provide only local monitoring. Despite the various types of NDT available, its selection depends on the application because each NDT method has advantages and disadvantages. It is a significant measure only if the comparison of NDT method is referred and compared with the 
corresponding task. The NDT methods frequently used for assessing damage in structures include the acoustic emission technique [1]-[4] ultrasonic technique [5]-[7] x-ray technique [8], [9], eddy current [10] and high speed video camera to obtain modal parameter of monitored structure [11], [12].

On the other hand, damage identification based on vibration characteristics is beneficial because changes in structure can be monitor in global basis. The basic principle of the SHM system is the damage in the structure alters the stiffness, mass and damping which consequently alter the dynamic response of the structure [13]. SHM is acknowledged as a commendable non-destructive evaluation technique for ensuring structural safety and reliability in civil engineering. Researchers and engineers have employed the SHM technique widely using modal analysis to monitor damages in structures, with many studies recognising modal parameters as a promising tool to indicate damage in structures.

Fan \& Qiao, (2011) has reviewed damage identification based on vibration characteristics, classifying it into four major categories; 1) natural frequency based, 2) mode shape based, 3) curvature or strain mode shape based, and 4) methods combining both natural frequency and mode shape [14]. Modal curvature which is curvature of the mode shape has been successfully utilize to detect damage in beam structure [15]. Further, the damage detection algorithm has been adapted to detect anomalies in mode shapes of the beam structure [16].

The presence of damage in structures leads to decreased stiffness, which consequently causes a reduction in the natural frequencies of the system. Changes in the natural frequency is a prevalent method of structural damage assessment in modal analysis. This method is particularly advantageous when implemented in a real structure, as natural frequency can be obtained by simple measurement from a few accessible points. Furthermore, Salawu (1997) reviewed structural damage detection through changes in natural frequency, concluding that the changes alone might be insufficient to identify the location of damage.

Utilising mode shape as a damage indicator is currently garnering much attention as its characteristics can provide local information, rendering it sensitive towards the presence of local damages. Mode shape localisation in the damaged region is highly dependent on the severity and location of damage on the mode being observed. If the damage is located in nodal nodes, which is the zero point of displacement of the observed mode, only minimal localisation of the mode shape is observed. The advantage of employing the mode shape approach as the damage assessment indicator is its independence of environmental effect such as temperature when compared to natural frequencies [18].

Mazurek \& DeWolf, (1990) conduct the experimental study of bridge monitoring technique and summarize that the deviation of frequency was increase as the increase of crack depth and there are highest change of mode shape in surrounding damage area [19].
Mannan and Richardson, (1990) found that the higher order mode possess higher sensitivity towards the local changes that occur in the structure [20].

This paper studies the vibration characteristics of pipe structures exhibiting corrosion and the resultant loss of thickness. The focus is on changes in the dynamic characteristics of pipe structures undergoing loss of thickness based on artificial damage case simulation. The method of finite element utilising the Abaqus software has been adapted to conduct the modal analysis. The deviation of natural frequency and mode shape obtained from the baseline intact model are compared to a damaged model and have been set as the feature of damage identification in this study.

\subsection{METHODOLOGY}

The present study evaluates the free vibration of pipe structures. The resulting natural frequencies reduction and mode shape sensitivity according to different size, location and level cut off thickness of damage present in the pipe model are examined.

\subsection{Finite Element Models and Modal Analysis}

The pipe model has been constructed using a threedimensional (3D) finite element analysis (FEA) with a programming language called Abaqus, version 6.14. To obtain the natural frequencies and mode shapes, eigenvalue analysis has been performed, with the use of Lanczos eigen-solver to solve the matrices. The material properties of the steel being considered in this study are: density, $\rho=7850 \mathrm{~kg} / \mathrm{m}^{3}$; Poisson's ratio, $v=$ 0.3 ; and Young's modulus, $\mathrm{E}=210 \mathrm{GPa}$. The dimension of the pipe is $1.2 \mathrm{~m}$ in length with an outer diameter of $406.4 \mathrm{~mm}$, and intact thickness of $9 \mathrm{~mm}$. The characteristics of the pipe was set follow the real size of pipe structure except length of the pipe. The interest damage inspection on this pipe is $1.2 \mathrm{~m}$ in length. The pipe model was set to S4R elements, which consist of four node conventional shell elements with reduced integration. The boundary condition was set as simply supported.

\subsection{Damage Case Simulation}

In this investigation, the damage assessment has been conducted numerically from artificial damage case simulation. The size, position and depth of loss of thickness varied for different damage cases. The thickness of element was set as constant in the intact pipe model. On the other hand, for the damaged model, the thickness of the element in the damaged region was reduced to achieve the reduction in stiffness. The cut off depth in the damaged region for each damage was increased from intact up to $75 \%$ thickness loss to represent the increase in the severity of damage. In total, six damage cases were evaluated with two different sized damage areas and three different positions of damage. 
The effect of damage on frequency change was expressed in a simple non-dimensional correlation between the baseline model and damaged model. This correlation has been determined as the percentage of frequency change which was described in Equation 1.

$$
\mathrm{R}(\%)=\frac{\omega_{\mathrm{u}}-\omega_{\mathrm{d}}}{\omega_{\mathrm{u}}} \times 100
$$

In Equation (1), wu represents the natural frequency for the undamaged model, while $\omega_{d}$ represents the natural frequency for the damaged model.

\subsubsection{Position of Damage}

The position of damage varied to the study effect of damage position on the changes in the modal parameters. Figure 1 summaries the position of damage in the pipe structure. The damage was located at the middle, quarter and end of the structure, representing damage case 1, damage case 2 and damage case 3 respectively. Symbol $x$ is denoted as the distance of damage from the end of the structure.

\subsubsection{Size of Damage}

The size of damage is another parameter that was varied in the artificial damage model. The size of the damage was categorised as small and large. Small damage represented localised damage and was set as $2 \%$ of the total area of the structure. On the other hand, the large damage was set as $10 \%$ of the total area.

Figure 2 represents the artificial damage case scenario in the pipe model with a designated area of reduced stiffness. In each size and position of damage, three stages of thickness reduction were applied which are $25 \%, 50 \%$ and $75 \%$ reduction.

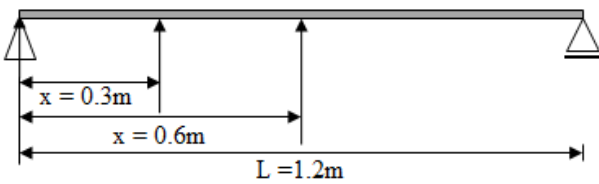

Figure 1 Damage case scenario on pipe structure

Elements with reduced thickness
Damage case la: $2 \%$ area of the
thickness reduction was considered
at center part of the pipe

Figure 2 Details of damage case scenario in pipe structure

\subsection{RESULTS AND DISCUSSION}

Pipe damage may occur on both the internal and external surfaces in a corrosion prone environment. In this study, the damage was set from the external surface of the pipe structure. The damage assessment utilising modal identification was advantageous because the monitoring can be conducted during the operation. This method saves time and cost and avoids unnecessary cessation of operations.

\subsection{Modal Analysis of Baseline Pipe Model}

This section highlights the element of the steel pipe vibration mode of selection to further investigate structural changes. Excitation of the lower modes of vibration constituting the lower frequency represents the global assessment of the structure which has the advantage of detecting local changes in the structure if any. However, excitation of higher modes are more sensitive to the presence of damage, but it is difficult to measure in practice [21]. To excite a higher mode requires more energy compared to the excitation of 
several lower modes. Further, the excitation of a higher mode may cause damage to the structure.

Deviation of natural frequency and mode shape of the structure can be observed when damage is inflicted, altering the geometrical properties and mass properties of the structure. Clearer evidence of frequency changes and localisation of damage in mode shape are expected in areas displaying more severe damage, as per the severe corrosion that occurs in the splash zone of the marine structure. The presence of damage is detectable by frequency reduction, while location and size of damage can be predicted as per mode shape change from the baseline model.

Table 1 represents the results of the first ten modes of intact pipe mode. Couple mode 1 and mode 2, couple mode 3 and mode 4 , couple mode 5 and mode 6 , couple mode 7 and mode 8 , and couple mode 9 and mode 10 are identical modes having similar natural frequencies but having slightly different patterns of vibration. Thus, to further evaluate the effect of dynamic properties on damage in the pipe structure, only one mode from each of the first eight couple modes was considered.

Figure 3 represents the circular cross section of the steel pipe during the vibration for mode 1 , mode 3 , mode 5 and mode 7 . In the breathing mode, the pipe extends radially around its circumference. There are two lobe shapes in mode 1, three lobe shapes in mode 3 and mode 5, and four lobe shapes in mode 7, as per the results of the cross section figure. Mode 3 and mode 7 have the same vibration pattern, but mode 7 showed two independent regions of vibration in the axial direction. Mode 7 has a higher independent region of vibration compared to mode 3 .

Table 1 Natural frequency of the first ten mode of intact pipe model

\begin{tabular}{|c|c|}
\hline Mode Number & Natural frequency $\mathbf{( H z )}$ \\
\hline 1 & 362.50 \\
\hline 2 & 363.31 \\
\hline 3 & 525.81 \\
\hline 4 & 525.85 \\
\hline 5 & 720.49 \\
\hline 6 & 720.59 \\
\hline 7 & 947.76 \\
\hline 8 & 947.76 \\
\hline 9 & 1029.67 \\
\hline 10 & 1029.67 \\
\hline
\end{tabular}

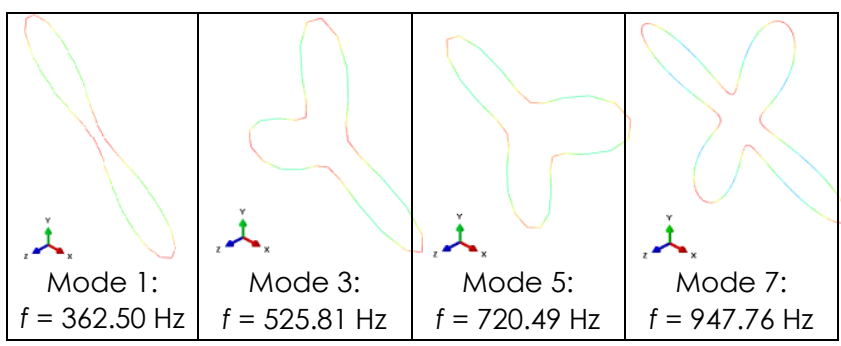

Figure 3 Circular cross section of steel pipe during vibration

\subsection{Modal Analysis of Damage Pipe Model}

\subsubsection{Damage Case 1}

The change in natural frequency is one of the indicators of the existence of damage in the structure. With $2 \%$ of designated damage area in the pipe model, the reduction in natural frequency can be observed. Figure 4 presents the graph of frequency change in the $2 \%$ size of damage case 1. In damage case 1, the damage was located in the middle part of the pipe. The higher deviation of natural frequency was observed in mode 5 with $75 \%$ of thickness reduction. Overall, the deviation of natural frequency was small around $1 \%$ for all three levels of cut off depth.

Figure 5 summarises graphically the change of mode shape due to $2 \%$ damage. The $2 \%$ damage area does not show distinct changes in mode shape from the baseline model. Small localisation occurred in mode shape resulted from the $75 \%$ of thickness reduction for mode 1, mode 3 and mode 7. On the other hand, mode 5 does not show any localisation of mode shape since the damage was located in the passive region of this mode. The dark blue areas in mode shape figures indicate passive vibration region for the observed modes of vibration which represent the areas with the displacement value is close to zero. Since damage areas have lower stiffness compared to the surrounding region, it causes the dominant vibration to occur in this severely damaged region. A clearer observation of frequency change and localisation of damage mode shape was expected in more severely damaged areas, indicating a higher percentage of damage area.



Figure 4 Deviation of natural frequency in the first eight mode of steel pipe tube for damage case 1 of $2 \%$ designated area

Figure 6 shows the graph of deviation of natural frequency in $10 \%$ damage area for damage case 1 . The results show that the deviation in natural frequency increases with increases in the level cut of depth in the damaged region. The pipe with $75 \%$ thickness reduction showed the highest deviation of frequency as compared to $50 \%$ and $25 \%$ thickness reduction. Mode 7 shows the higher deviation of natural frequency 
followed by mode 3 . On the other hand, mode 2 shows the lowest deviation of natural frequency indicating that this mode is less sensitive towards the presence of damage case 1.

Additional assessment based on mode shape results was conducted as shown in Figure 7. The large switch in mode shape has been expected to occur around the damaged region, which is invaluable for the prediction of the location of damage in the structure for further investigation. At first, when small damage of $25 \%$ of thickness reduction was introduced to the pipe model, there was no distinct change between the damaged model and reference model. With an increase in the level cut off depth to half of the thickness, there was clear localisation in local mode 7 . Mode 7 represents the more localised mode of vibration among others modes which possessed a higher number of independent vibrations in the region. The mode shape localisation in this particular mode due to damage was more apparent compared to mode 1, mode 3 and mode 5. Further, as the level cut off depth increased to $75 \%$ thickness reduction, more localisation occurred in local mode 7. There was almost zero vibration in surrounding damaged regions, and the vibration was dominant only in the damaged region.



(i) Intact model

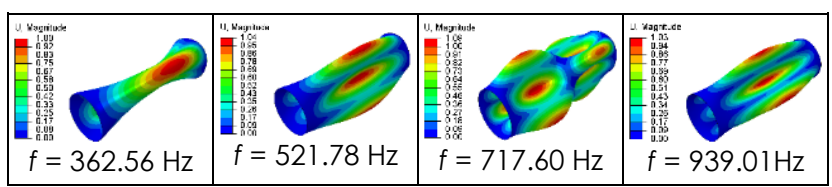

(ii) $25 \%$



(iii) $50 \%$

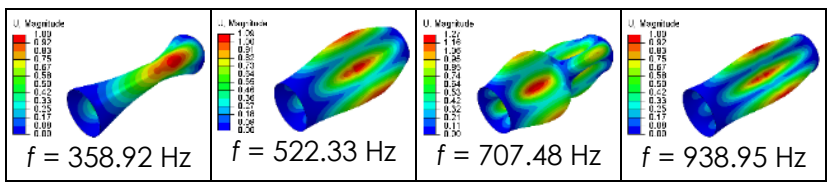

(iv) $75 \%$

Figure 5 Pattern switch in mode shape due to $2 \%$ designated area of damage case 1 in steel pipe



Figure 6 Deviation of natural frequency in the first eight mode of steel pipe tube for damage case 1 of $10 \%$ designated area



(i) Intact model

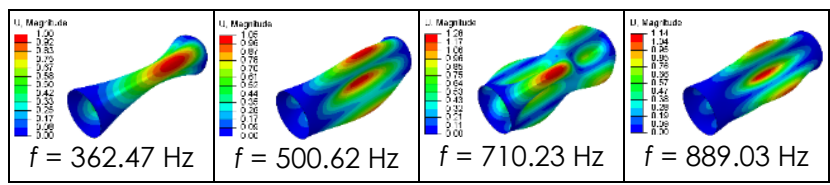

(ii) $25 \%$

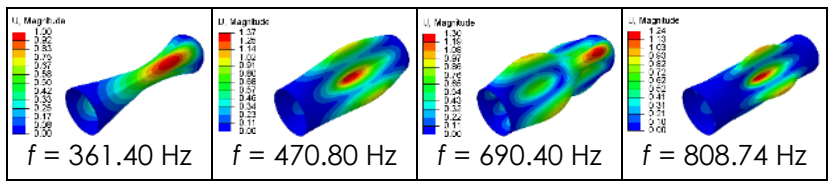

(iii) $50 \%$

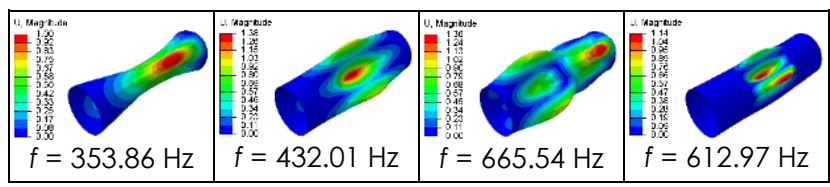

(iv) $75 \%$

Figure 7 Pattern switch in mode shape due to $10 \%$ designated area of damage case 1 in steel pipe

\subsubsection{Damage Case 2}

In damage case 2, the position of damage was switched to the quarter end of the pipe. A clear pattern switch of frequency deviation cannot be obtained when only small damage was introduced to the system as $2 \%$ of damage in damage case 2 . This is illustrated in the graph of frequency deviation in Figure 8. It was supposed that with increases in damage severity, there would be an increase in the reduction of natural frequency. In this case, the highest frequency deviation occurred in mode 1 for $75 \%$ of thickness reduction with a value of $1.41 \%$. The average value of frequency deviation was around $0.5 \%$ and below. 
Figure 9 displays the pattern switch in mode shape due to $2 \%$ damage in the steel pipe model. The damage was placed in the dominant vibration region of mode 5. Due to the vibration pattern of mode 5, it was predicted that mode 5 was the more sensitive mode compared to mode 1 and mode 3 . With the introduction of $2 \%$ damage, there was little localisation of mode shape in the damaged region.

In this stage, the damage size increased from $2 \%$ to $10 \%$ to study the effect of the size of damage in case 2 . Figure 10 displays the results of frequency change in three level cuts of depth. In large damage case simulations, it was clear that increased levels of damage increased the frequency deviation. Mode 7 and mode 5 show the higher sensitivity based on the higher deviation of frequency.

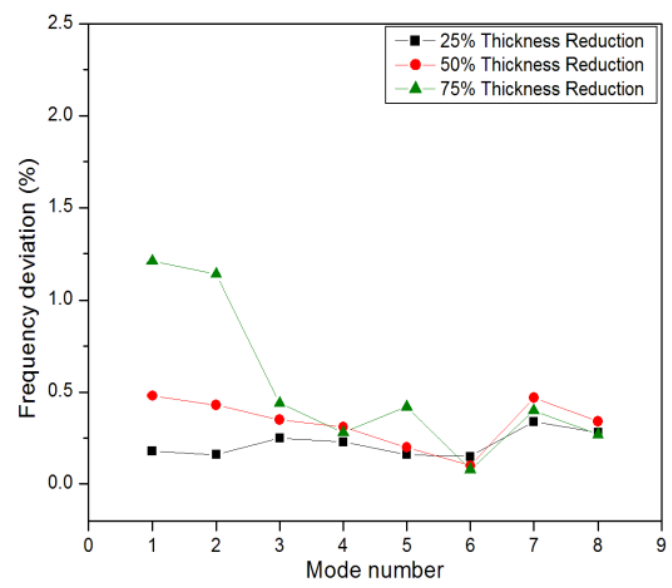

Figure 8 Deviation of natural frequency in the first eight mode of steel pipe tube for damage case 2 of $2 \%$ designated area
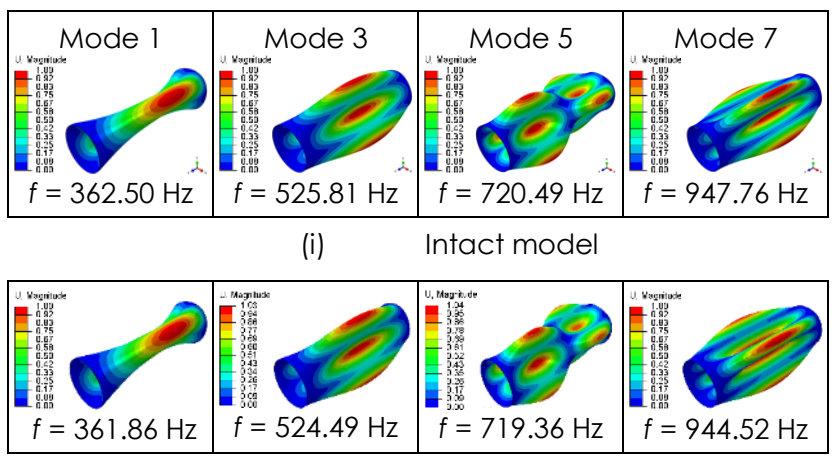

(ii) $25 \%$

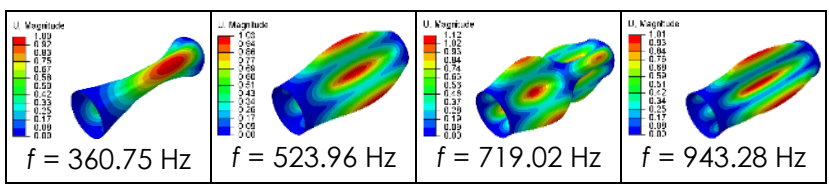

(iii) $50 \%$

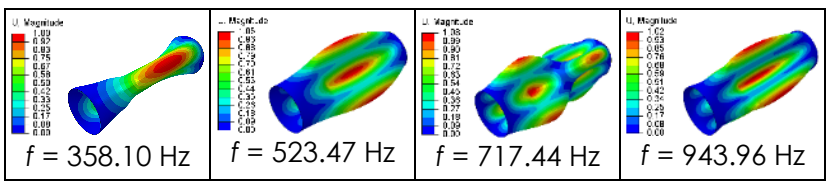

(iv) $75 \%$

Figure 9 Pattern switch in mode shape due to $2 \%$ designated area of damage case 2 in steel pipe
Figure 11 shows the mode shape deviation with the introduction of $10 \%$ damage in case 2. Mode 7 shows large deviation in $25 \%$ of thickness reduction. Further, with the increase of another $25 \%$ of thickness reduction, the vibration started to dominate the damaged region. At the last stage, in $75 \%$ of thickness reduction, the mode was localised only in the damaged region with zero displacement surrounding the designated damaged region.

\subsubsection{Damage Case 3}

The damage was located at the end of the pipe in damage case 3 . The effect of the position, size and level cut of depth towards the modal parameter was further assessed in this damage case simulation. Figure 12 shows the deviation of natural frequency for small size of damage case 3 . With the increase in thickness reduction, the frequency deviation also increased. Couple mode 1 and mode 2 shows higher deviation in natural frequency compared to others modes followed by couple mode 5 and mode 6. Couple mode 7 and mode 8 shows less frequency deviation indicating that this mode is less sensitive to the presence of damage case 3

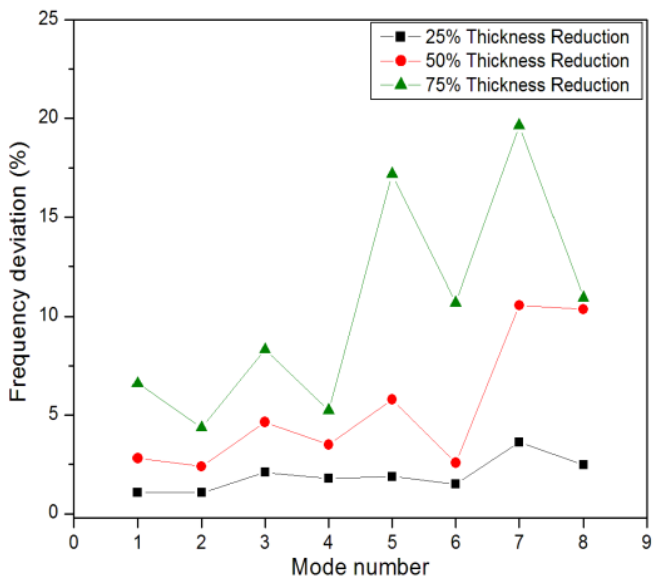

Figure 10 Deviation of natural frequency in the first eight mode of steel pipe tube for damage case 2 of $10 \%$ designated area

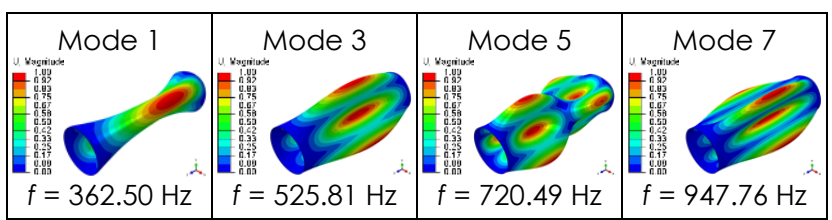

(i) Intact model

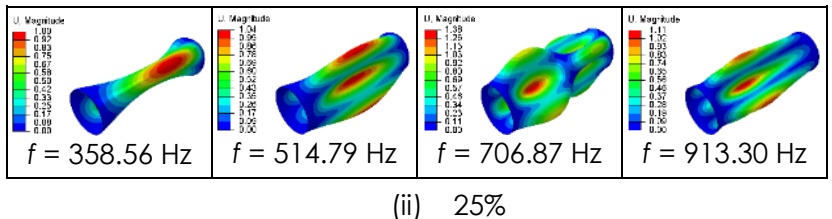




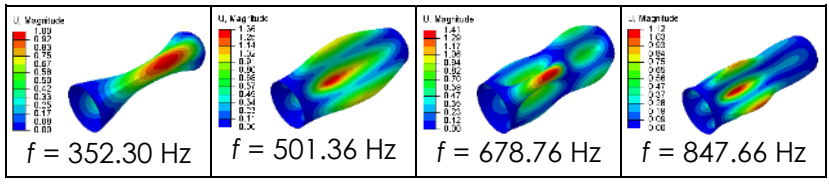

(iii) $50 \%$



(iv) $75 \%$

Figure 11 Pattern switch in mode shape due to $10 \%$ designated area of damage case 2 in steel pipe

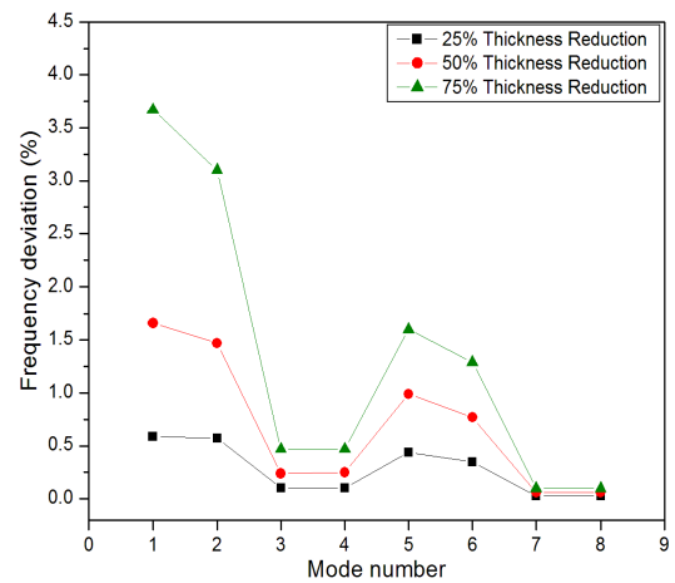

Figure 12 Deviation of natural frequency in the first eight mode of steel pipe tube for damage case 3 of $2 \%$ designated area

Further, Figure 13 present the switch of the mode shape toward this damage. Regarding the switch of the mode shape towards this damage, the dominant vibration region tends to switch to the damaged region with increases in the severity of damage.

The pattern of frequency change was not the same between small damage and large damage sizes. Figure 14 shows the deviation in natural frequency when the damage areas increased to $10 \%$. In this case, mode 7 followed by mode 5 show higher deviations in frequency which is different from the lower state of damage observed in Figure 12. In $25 \%$ of thickness reduction, the frequency deviation between each mode extracted was minimal.

Figure 15 summarises the effect of damage case 3 in a $10 \%$ damage area in terms of mode shape. Mode 7 shows the higher localisation of mode shape in the damaged region whereas mode 1 and mode 3 only slightly deviate from the intact case.

All things considered, the presence of a cut off in the pipe model case was detected by the modal parameter. Thus, changes in main modal parameters like frequency and mode shape can be further used as indicators of the presence of damage in structures.

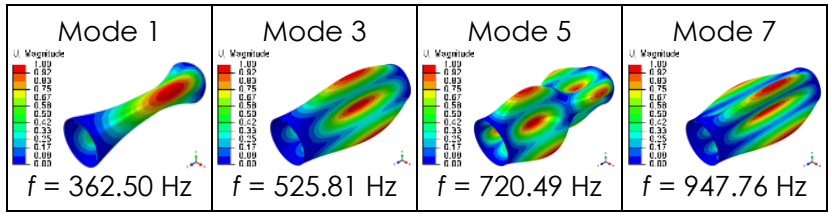

(i) Intact model

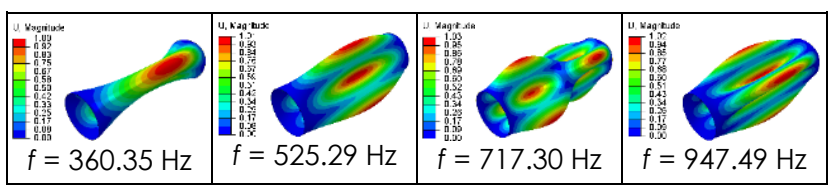

(ii) $25 \%$



(iii) $50 \%$

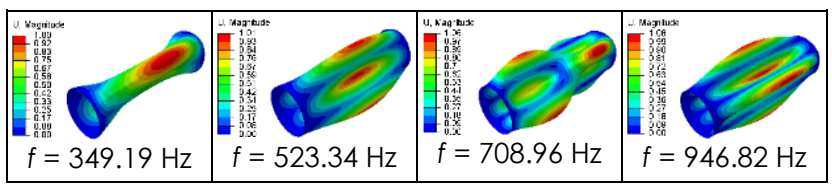

(iv) $75 \%$

Figure 13 Pattern switch in mode shape due to $2 \%$ designated area of damage case 3 in steel pipe

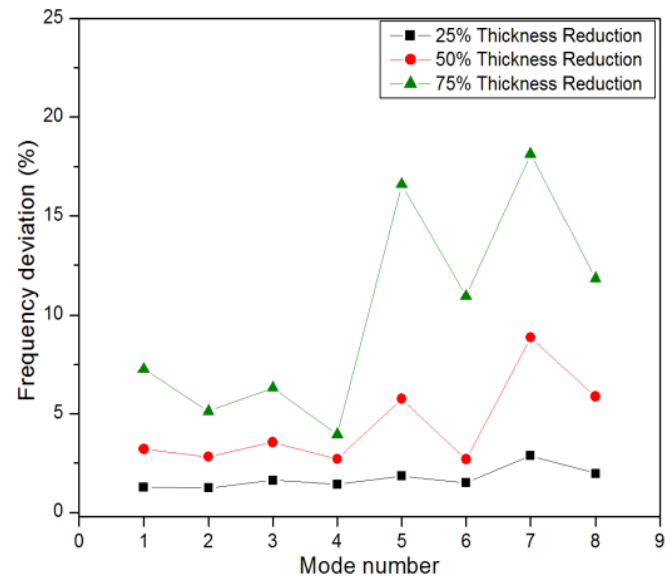

Figure 14 Deviation of natural frequency in the first eight mode of steel pipe tube for damage case 3 of $10 \%$ designated area

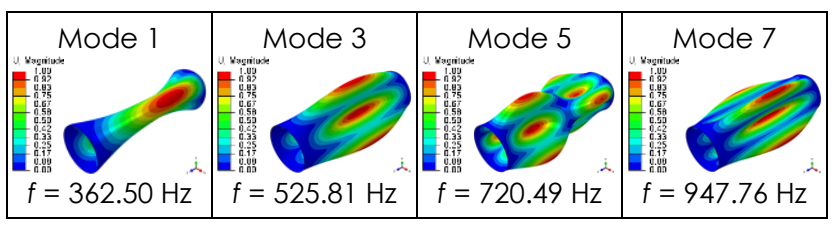

(i) Intact model

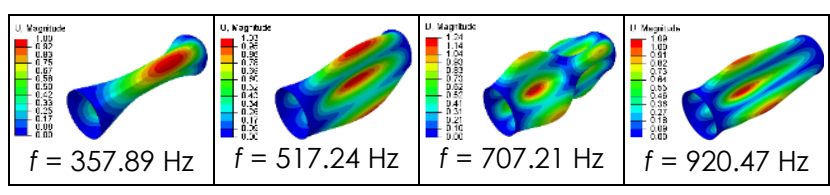

(ii) $25 \%$ 


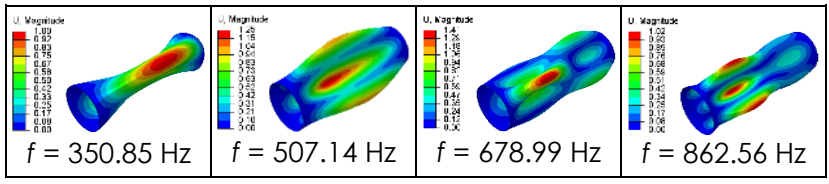

(iii) $50 \%$

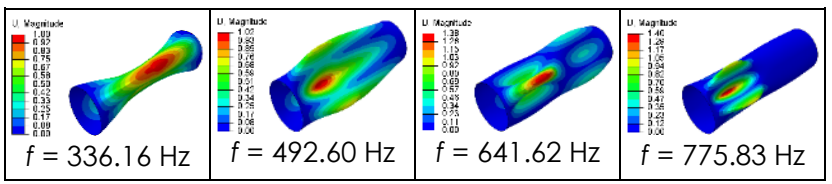

(iv) $75 \%$

Figure 15 Pattern switch in mode shape due to $10 \%$ designated area of damage case 3 in steel pipe

\subsection{CONCLUSIONS}

This study evaluated the degradation of steel structures due to the thickness reduction of pipe structures. It was observed that the changes in natural frequency take place with the presence of damage in the structure. The higher the deviation in natural frequency from the intact model represents higher damage in the structure. Additionally, localisation of mode shape in the damaged region can provide information regarding the location and size of the damage. The higher localisation of mode shape in the damaged region occurs with higher severity of damage. Moreover, the great switch in mode shape from the intact model occurred in higher orders of mode. All in all, significant reduction and deviation of natural frequency and localisation of mode shape lead to the determination of the presence, location, and size of the structural damage in the pipe structure. However, this strongly depends on the severity of damage.

\section{Acknowledgement}

The first authors wish to acknowledge support from Ministry of Higher Education Malaysia and Universiti Teknologi Mara, (UiTM) for the PhD scholarship grant.

\section{References}

[1] Shahidan, S., Abdullah, S. R. and Ismail, I. 2016. Relationship between AE Signal Strength and Absolute Energy in Determining Damage Classification of Concrete Structures. Jurnal Teknologi. 78(5): 91-98.

[2] Yu, L. and Li, S. Z. 2017. Acoustic Emission (AE) Based Small Leak Detection of Galvanized Steel Pipe Due to Loosening of Screw Thread Connection. Applied Acoustics. 120: 85-89.

[3] Suzuki, T., Shiotani T. and Ohtsu, M. 2017. Evaluation of Cracking Damage in Freeze-thawed Concrete Using Acoustic Emission and X-ray CT Image. Construction Building Material. 136: 619-626.

[4] Aldahdooh, M. A. A., Bunnori, N. M. and Johari, M. A. M. 2012. Damage Assessment of Reinforced Concrete Beams at
Different Flexural Damage Levels Using Acoustic Emission Technique. Malaysian Construstion Research Journal. 11 (2): 79-90.

[5] Blachowski, B., Swiercz, A., Gutkiewicz, P., Szelazek, J. and Gutkowski, W. 2016. Structural Damage Detectability Using Modal and Ultrasonic Approaches. Measurement. 85: 210221.

[6] Pahlavan, L. and Blacquière, G. 2016. Fatigue Crack Sizing in Steel Bridge Decks Using Ultrasonic Guided Waves. NDT\&E International. 77: 49-62.

[7] Eybpoosh, M., Berges, M. and Noh, H. Y. 2017. An EnergyBased Sparse Representation of Ultrasonic Guided-waves for Online Damage Detection of Pipelines under Varying Environmental and Operational Conditions. Mechanical System and Signal Processing. 82: 260-278.

[8] Pinheiro, B., Lesage, J., Pasqualino, I., Benseddiq, N. and Bemporad, E. 2012. X-ray Diffraction Study of Microstructural Changes during Fatigue Damage Initiation in Steel Pipes. Material Science and Engineering A. 532: 158-166.

[9] Lyubimova, L. L., Fisenko, R. N., Tabakaev, R. B., Tashlykov, A. A. and Zavorin, A. S. 2017. X-ray Investigation of a Heterogeneous Steel Weld. Material Science Engineering A. 682: 248-254.

[10] Liang, T., Ren, W., Tian, G. Y., Elradi, M. and Gao, Y. 2016. Low Energy Impact Damage Detection in CFRP Using Eddy Current Pulsed Thermography. Composite Structure. 143: 352-361.

[11] Chen, J. G., Wadhwa, N., Cha, Y. J., Durand, F., Freeman, W. T. and Buyukozturk, O. 2015. Modal Identification of Simple Structures with High-speed Video Using Motion Magnification. Journal Sound Vibration. 345: 58-71.

[12] Chen, J. G., Wadhwa, N., Cha, Y. J., Durand, F., Freeman, W. T. and Buyukozturk, O. 2014. Structural Modal Identification through High Speed Camera Video: Motion Magnification in: J. De Clerck (Ed.). Topics in Modal Analysis I, Conference Proceedings of the Society for Experimental Mechanics Series. Springer International Publishing. 7: 191-197.

[13] Farrar, C. R., Doebling, S. W. and Nix, D. A. 2001. VibrationBased Structural Damage Identification. Philosophical Transactions Mathematical Physical and Engineering Science. 359(1778):131-149.

[14] Fan W. and Qiao P. 2011. Vibration-based Damage Identification Methods: A Review and Comparative Study. Structural Health Monitoring. 10(1): 83-111.

[15] Yang, Z. B., Radzienski, M., Kudela, P. and Ostachowicz, W. 2017. Fourier Spectral-based Modal Curvature Analysis and Its Inspection to Damage Detection in Beams. Mechanical Systems and Signal Processing. 84: 763-781.

[16] Shahsavari, V., Chouinard, L. and Bastien, J. 2017. Waveletbased Analysis of Mode Shape for Stattistical Detection and Localization of Damage in Beams Using Likelihood Ratio Test. Engineering Structures. 132: 494-507.

[17] Salawu, O. S. 1997. Detection of Structural Damage through Changes in Frequency: A Review. Engineering Structural. 19(9): 718-723.

[18] Roberts, G. P. 1995. Recent Experience in Dynamic Monitoring of a Multi-Span Bridge. The Institution of Structural Engineers. Analysis \& Testing of Bridges. 41-43.

[19] Mazurek D. F. and DeWolf, J. T. 1990. Experimental Study of Bridge Monitoring Technique. Journal Structural Engineering (ASCE). 116(9): 2532-2549.

[20] Mannan, M. and Richardson, M. 1990. Detection and Location of Structural Cracks Using FRF Measurements. Proceedings of the $8^{\text {th }}$ International Modal Analysis Conferences. 652-657.

[21] Downer, L. M. and Rideout, D. G. 2011. A Design of Experiments Approach to Identifying Damage in Structures Using Modal Frequency. ASME International Mechanical Engineering Congress and Exposition. 1-10. 